\title{
Dimensional Accuracy of Digitalized Stone Models Obtained from Alginic Acid Polymer and Poly-dimethyl-siloxane Impressions
}

\author{
LUMINITA OANCEA ${ }^{1}$, CORINA MARILENA CRISTACHE ${ }^{2 *}$, \\ ALEXANDRU EUGEN PETRE ${ }^{1}$, EUGENIA PANAITESCU ${ }^{3}$, \\ MIHAI BURLIBASA ${ }^{2}$, LUCIAN TOMA CIOCAN ${ }^{4}$
}

${ }^{1}$ Carol Davila University of Medicine and Pharmacy, Faculty of Dental Medicine, Department of Fixed Dental Prosthetics and Occlusion, 19 Plevnei Av., 010221, Bucharest, Romania

${ }^{2}$ Carol Davila University of Medicine and Pharmacy, Faculty of Midwifery and Medical Assisting (FMAM), Department of Dental Techniques, 8 Eroilor Sanitari Blvd, 050474, Bucharest, Romania

${ }^{3}$ Carol Davila University of Medicine and Pharmacy, Faculty of Medicine, Department of Medical Informatics and Biostatistics, 8 Eroilor Sanitari Blvd, 050474, Bucharest, Romania

${ }^{4}$ Carol Davila University of Medicine and Pharmacy, Prosthesis Technologies and Dental Materials, 19 Plevnei Av., 010221. Bucharest, Romania

\begin{abstract}
The prognosis of the prosthetic rehabilitation is linked to the proper transfer of the clinical data to the dental laboratory, in the digital or conventional workflow. The aim of the present study was to compare the dimensional accuracy of analog and digitalized models, focusing on the influence of impression polymeric materials on the final digital model. Methods: The master model with standard reference points and the three groups of test models, obtained by alginic acid polymer impression (group A) and condensation-cured poly(dimethyl siloxane) in two impression techniques (1-step putty/lightbody-group 1T, 2-steps putty/ light-body-group 2T), were measured in four standardized points before and after digitization. The differences from the master model and between the pair analog and digital models was calculated and statistically analysed using Mann-Whitney tests (2 groups), and one-way Anova (3 groups) with post-hoc Tukey's Test was applied for pairwise analysis $(\alpha=0.05)$. Results: All analog and digitalized model tests showed altered dimensions from the master model. A general reduction of the digitalized models, in sagittal and transversal dimensions, was observed, comparing to the reference model. The impression material was a significant factor influencing dimensional accuracy. Conclusions: a statistically significant difference was found between most of the models and the master model. However, through digitalization, some of the errors were compensated. The digital models from alginic acid polymer group (group A) registered the highest trueness, with no statistically significant difference $(P>0.05)$ from the reference model.
\end{abstract}

Keywords: polymeric impression materials, alginic acid polymer, condensation-cured poly(dimethyl siloxane), Computer-Aided Design and Manufacturing, dental arch.

\section{Introduction}

Due to their excellent biocompatibility, satisfactory mechanical properties, and processability, polymers are used in different areas in dentistry, and have fundamental importance as dental impression materials, restorative materials, bone substitutes, or as accessory materials [1,2].

The prosthetic rehabilitation's success relies on the adequate data transfer from the clinical settings to the dental laboratory [3]. Various materials and techniques for achieving the most accurate models have been described in the scientific literature [4-6] but many possible errors may occur in this multistep process. From the choice of impression material, prone to setting dimensional changes, as well as the applied impression technique, the disinfection protocol, the transport, the type of gypsum used, the setting time, even the time spent between each single step, the indirect digitalization and so on, the entire

*email: corina.cristache@umfcd.ro

All authors have equally contributed to this paper 
process is crowded with plenty of possible mistakes, influencing the accuracy of the final prosthetic restoration.

Most of the impression materials used nowadays in daily practice are polymers, either belonging to hydrocolloid or elastomeric group, their choice being in accordance to the requirement of each particular case, and the knowledge of their structure and characteristics, will improve the predictability and hence avoid repeat impression/restorations.

The impression materials need to reproduce de detailed replica of the teeth and tissues of the oral cavity. To be used for impressions, the polymeric materials needs to have a certain viscosity to prevent displacement of soft tissues, hydrophilicity (a hydrophobic material will lead to holes in the impression surface due to trapped air), a low degree of polymerization shrinkage (to prevent obtaining larger crowns), slight thermal contraction (as it cools from mouth to room temperature), to be non-toxic, easily to be mixed, with short setting time, to be sufficiently flexible to allow removal from the undercut regions without causing distortion and also to have storage stability, to overcome the delay between the taking of an impression and its arrival in the dental laboratory where the model is poured [7].

The results of Samet et al. study [8] regarding the dimensional accuracy of the model stressed the requirement of a more critical evaluation of impressions for fixed prosthodontics, $90 \%$ of the tested models presenting one or more observable errors.

Advancements in CAD/CAM technology significantly improved the prosthetic rehabilitation process. The use of a partially or full digital workflow for prosthesis fabrication on a virtual threedimensional (3D) model became, nowadays, very popular. The virtual model could be obtained in the dental laboratory by scanning the conventional impression, the gypsum model or, directly, based on intraoral scanning of the dental structures [9].

The major aspect needed to be evaluated in the digitalization process is the accuracy. Accuracy is defined in terms of precision and trueness (ISO 5725-1) [10,11]. Precision describes the degree of reproducibility between repeated measurements, and trueness describes the closeness of agreement to the object being measured $[12,13]$.

The direct optical intraoral digitization has been proven to have high accuracy for full digital workflows of single crowns manufacturing, up to one quadrant $[14,15]$. Scientific literature reports concluded that the shorter the distance, the more accurate were virtual models compared to conventional ones $[16,17]$.

However, for the digital impressions of full-arch restorations, there is not enough scientific clarification [18]. Most of the published studies evaluating the registration of a full arch focused on comparing digital to conventional impression techniques either using extraoral or intraoral scanners $[19,20]$ or compared the accuracy of different extraoral [21] or intraoral scanners [22]. Generally, the methods used to compare the data and calculate the differences were based on best fit alignment, using different metrology software with contradictory results [20,22,23], based on the superimposition algorithms of the used software.

Moreover, the absence of marked reference points and the solely use of virtual marks, as cusps or fossae, could lead to significant differences between measurements with low intra- and interobserver reliability $[24,25]$.

Recently, for comparing full-arch digital impressions to conventional impressions in vitro and in vivo a metal bar was mounted between the first and the second maxillary molar with the aim of improving the trueness assessment [19], but without marking any reference for the anterior sextants.

There are several reasons why the partially digital workflow, including conventional impression taking, gypsum pouring, and indirect digitalization in the dental laboratory is still preferred in most dental practices. Among the main reasons, it can be note the high costs of the equipment, and the learning curve required for its correct use [18,26]. But, also, some clinical circumstances including large edentulous area or reflective surfaces such as metallic restorations, among others, may require conventional impression techniques [27,28]. 
On the other hand, even with digital workflow, the physical model is needed in certain cases. One example is the requirement of a model for the post processing of a surgical template used in static guided surgery. In such case, the accuracy of the implant positioning is dependent on sum of all errors occurring from clinical examination to the template execution, one of the key factors being the digitalized model [9].

Because in most of the complex prosthetic rehabilitations, orthodontic treatments, or dental implants insertion and restorations, the transfer data of a full arch is required, and the information on the influence of indirect digitalization of models poured from different impression materials and techniques is scarce, we aimed, in the present study, to compare the dimensional accuracy of analog models and digitalized full arch models, obtained by laboratory scanning technique. The influence of the material on scanning accuracy was also evaluated. The null hypothesis was that there were no statistically significant differences in the linear dimensions between the master model and the conventional and digital models acquired via digitalization of stone models obtained from different impression techniques and materials.

\section{Materials and methods}

\subsection{Materials}

A basic maxillary study model (typodont, KaVo Dental GmbH, Biberach, Germany), with marked occlusal morphology of teeth, made of plastic reflective material, mounted in a DSETM Expert dental training simulation unit (KaVo Dental $\mathrm{GmbH}$, Biberach, Germany), was used as master (reference) model. Four standard reference points were set as follows: two on the anterior sextant, on the cusp tip of the right and left canines and one on the posterior sextant of each side (left and right), on the mesiovestibular cusps tips of the left and right first molar. The four references points were marked by grinding hemispherical landmarks (1.4-mm diameter) with a round burr.

Two type of impression materials were used: condensation-cured polymethyl siloxane (PDS) impression material (Speedex, Coltene, Switzerland), in two consistency (two phase): putty and light body with Universal Activator and Coltene Adhesive; and an alginic acid polymer (AAP), monophase impression material (Elastic Cromo, Pentron, USA).

The condensation-cured silicone used in the present study is based on polymethyl siloxane, a synthetic elastomer with a molecular chain composed of alternating silicon and oxygen atoms (-Si-O$\mathrm{Si}-$ ), and belongs to the same group as addition-cured silicones, but having different end-groups, leading to different curing mechanisms [7]. The chemical composition of the condensation PDS is presented in Figure 1a [2]. The siloxane polymer contains hydroxyl terminal groups and the crosslinking is achieved with a tetraethyl silicate; the by-product of this reaction being an alcohol $(\mathrm{R}-\mathrm{OH})$. The polymeric material is available in a range of viscosities, depending on the amount of filler that is incorporated, putty and light body were used in our study.

The monophase impression material, alginate is based on alginic acid, a polysaccharide extracted from the cell walls of brown algae. Alginic acid is a linear copolymer with homopolymeric blocks of (14)-linked $\beta$-D-mannuronate and its C-5 epimer, $\alpha$-L-guluronate. The setting process is a cross-linking chemical reaction, converting the sol to a gel, and is initiated by the release of $\mathrm{Ca}$ ions from Calcium sulphate dihydrate. The polymeric network, formed with the calcium ions bridge has the poly(guluronate) and the poly(mannuronate) segments in an "egg-box" configuration (Figure 1b) [29]. Beside the above-mentioned components, the commercial product also contains: Sodium phosphate for controlling working time; Potassium sulphate as setting aid, Sodium silicofluoride for controlling $p \mathrm{H}$, other fillers such as diatomaceous earth for controlling consistency.

Type IV (Elite rock, Zhermack SpA, Polesine, Italy) dental stone (gypsum) was used for pouring all the models. 


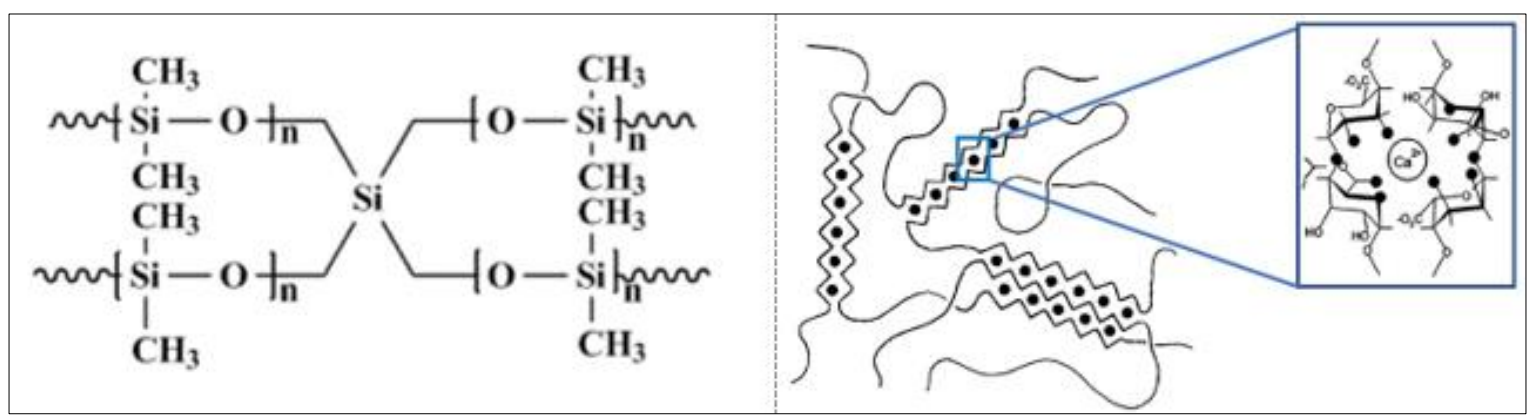

Figure 1. Chemical formulas: a. condensation-cured polymethyl siloxane; b. alginic acid polymer in "egg-box" configuration

\subsection{Equipment}

Arctica dental 3D scanner (KaVoDental GmbH, Biberach, Germany), using precise striped light projection technology was employed to digitalize the gypsum models and master (typodont) model.

A digital caliper (Digimatic Caliper: CD-15CPX; Mitutoyo, Kawasaki, Japan) with an accuracy of $0.01 \mathrm{~mm}$, was used to perform the direct (analog) measurements.

EXOCAD® DentalCAD, version 2.3 Matera software (Exocad GmbH, Darmstadt, Germany) was used for digital linear measurements.

\subsection{Methods}

The present study was divided in four stages as follows: (1) impression procedure, producing and (2) digitization of three categories of models and the master model, (3) four standardized linear measurement for each sample, (4) comparisons and statistical analysis.

\subsubsection{Impression and model fabrication procedure}

Thirty conventional impressions of the reference model were taken as follow: ten impressions with a two-consistency one-step technique using the condensation PDS polymeric impression material (1T), ten impressions with a two-consistency two steps technique using same condensation-cured PDS polymeric impression material (2T) and ten impressions with alginic acid polymer (A).

All impressions were taken by a single calibrated operator from the same 9 o clock clinical position with a two fingers palatal pressure. Metal perforated L size stock trays (Zhermack SpA, Polesine, Italy) were used and, for PDS impressions, adhesive was applied with five brush strokes (approximately 0.2 $\mathrm{mL}$ per tray) [30]. The material preparation was performed according the manufacturer recommendations. A timer for a controlled setting was used and impressions were made under standard clinical conditions of temperature and relative humidity $\left(23 \pm 2{ }^{\circ} \mathrm{C}\right.$ and $\left.50 \pm 10 \%\right)$ [31]. The same volume of impression material was employed each time to standardize the study.

Two techniques were used for the condensation PDS two phase material: one-step (1T) and twosteps (2T). For the one-step technique, putty and light body were mixed with universal activator and applied at the same time, whereas for the two-step technique the putty impression is taken first and after setting, $2 \mathrm{~mm}$ space was created with scalpel in the made impression and mixed light body material was applied for the second impression [32].

After setting time, the impression trays were removed from the reference model and inspected for defects. All impressions with observable defects or with missing landmarks were repeated.

The gypsum models were manufactured in standard conditions as follows: The type IV Elite rock dental stone pre-weighed with added distilled water, according to the manufacturer's instructions, was mixed under vacuum using a Venturi Tornado effect mixer (Silfradent, Forlì-Cesena, Italy) and poured into the impression on a gypsum vibrator (Renfert, Hilzingen, Germany).

The casts were allowed to set 30 minutes for the AAP impression and $1 \mathrm{~h}$ for condensation PDS impression to allow the correct elastic recovery of impression materials [33], and then removed from the impression. 


\subsubsection{Digitization of the test models}

Digitization process of the reference model and the 30 test models was achieved with the same scanner, Arctica, with an accuracy ranging from 10 to $30 \mu \mathrm{m}$ [34], to obtain 31 scan files (virtual models) in standard tessellation language (STL) format. One single trained operator performed the scanning procedures for all models, including reference model, using the same settings and a powder free technique. The scanner was calibrated before each use according to the manufacturer' recommendations. The digital file of each model was than imported into Exocad software, where the measurements were performed.

\subsubsection{Linear measurements}

Four type of linear measurements were made using the centre of the reference marks: between the left and right canine cusps (CC); between the first molar's mesio-vestibular cusps left and right (MM); and between canine cusps and first molar's mesio-vestibular cusps left and right (CML and CMR, respectively).

Direct measurements (analog) were performed for the reference model and for each test gypsum model, using the digital caliper.

The digital measurements were done, for all digitalized models, using the dedicated Exocad tool for linear measurement [35] (Figure 2).

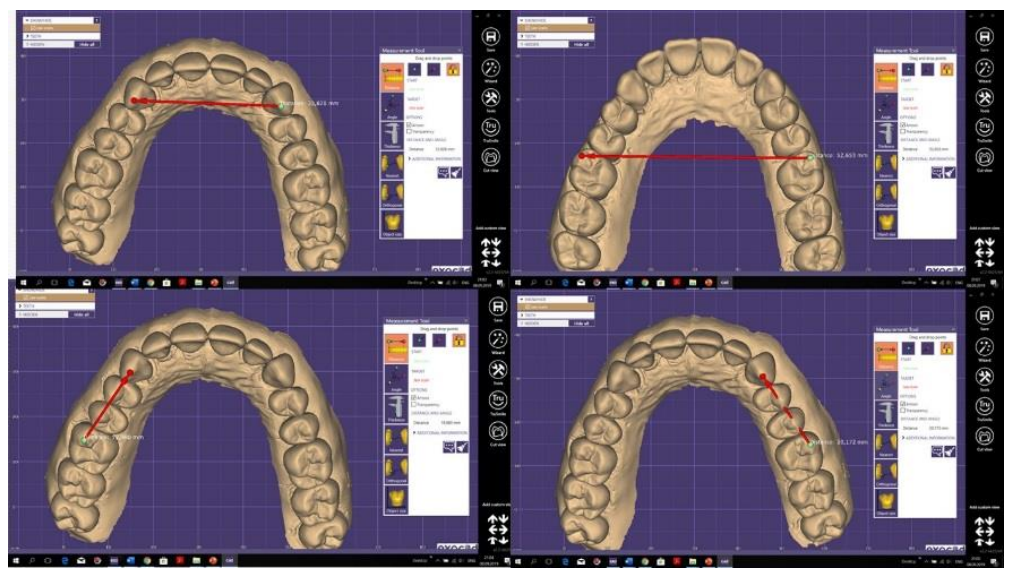

Figure 2. Linear digital measurements in Exocad between the left and right canine cusps (CC); between the first molar's mesio-vestibular cusps left and right (MM); and between the canine cusp and first molar's mesio-vestibular cusps right and left (CMR and CML, respectively)

Analog and digital measurements were performed three times for all models, under standardized conditions for each linear measurement, by a single operator, calibrated, before the experiment to a 0.8 Cohen's Kappa interrelated reliability coefficient. Three readings were made and the mean of the three values were calculated. All measurements were recorded to the nearest $0.01 \mathrm{~mm}$.

The master model and its digital file were measured, using the same analog and digital protocol and the mean of each three consecutive measurements was set as reference (Figure 3).

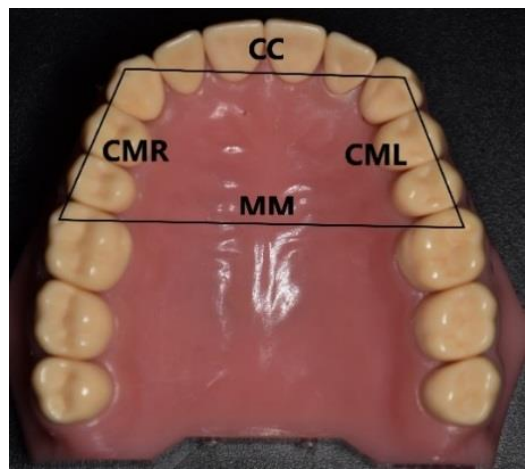

Figure 3. Linear analog measurements of the master (reference) model in the center of the marked landmarks: between the left and right canine cusps (CC); between the first molar's mesio-vestibular cusps left and right (MM); and between the canine cusp and first molar's mesio-vestibular cusps right and left (CMR and CML, respectively) 


\subsubsection{Comparisons and statistics}

All measurements were synthetized in an Excel table, compared and analysed. Origin Lab Pro 2019 (OriginLab Corporation, Northampton, MA, USA) was used for statistical analysis. The study workflow is presented in Figure 4.

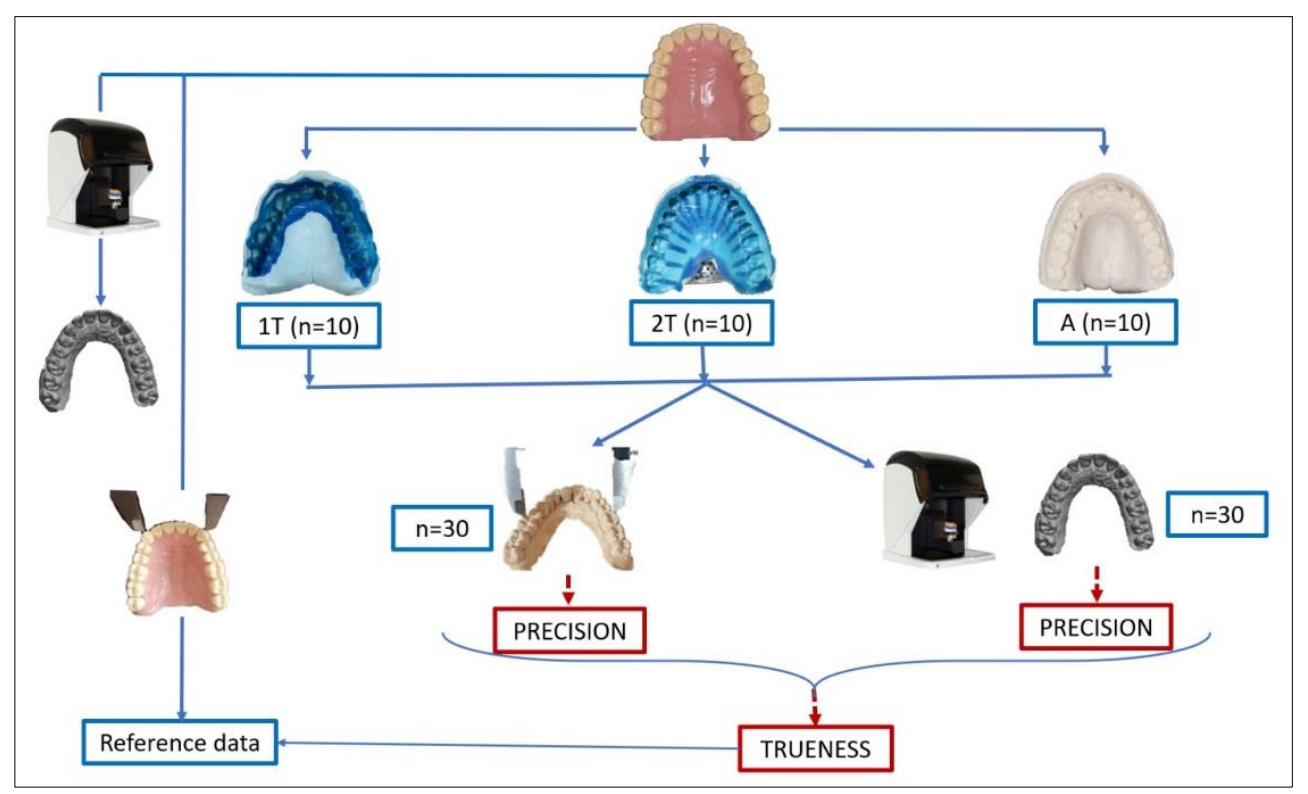

Figure 4. Flow-chart of the study design $1 T=$ PDS impression in one-step technique,

2T= PDS impression in two-steps technique, A= AAP impression. Precision was evaluated between the mean values of each analog/digital tested group assessing the degree of reproducibility.

For trueness, all the analog and digital models were compared to the analog measurements of the reference model, set as reference data

Mean values, standard deviation and confidence interval were calculated for each group. Mean value of each individual measurement was also calculated and then compared with the original means obtained from the analog master model. The differences between the mean values of stone and digitalized models and master model were determined. If negative, the data indicated that there was decrease of the distances (shrinkage); if positive, it indicated volume increase (expansion).

Digital versus analog differences to each measurement level for each model type were obtained through Mann-Whitney tests for 2 groups, one-way analysis of variance (Anova) for 3 groups and posthoc Tukey's Test was applied for pairwise analysis $(\alpha=0.05)$. Levene's test was applied to assess normal distribution. $\mathrm{P}<.05$ was considered statistically significant.

The required sample size needed to attain a power of $80 \%$ was calculated to a minimum of 10 models, based on an acceptable difference between the mean and standard deviation (SD) of $0.2 \mathrm{~mm}$, based on the previous Kaihara' study results [36].

\section{Results and discussions}

\subsection{Precision evaluation of the different categories of models}

Table 1 shows the means, standard deviations and confidence interval, measurements of precision for the three groups of impression procedures and digitalized casts. To assess precision, the reproducibility of each type of model obtained from different types of polymeric impression materials were evaluated. The ten gypsum models, poured from the different polymeric impression materials and techniques, as well as the obtained digitalized models, were compared to each other. The lowest standard deviation $( \pm 0.11 \mathrm{~mm})$, showing high reliability, was determined for the gypsum model obtained from the one-step technique PDS impression used in this in vitro experiment. On the opposite site, the gypsum model poured from the alginic acid polymer impression registered the lowest precision, $\pm 0.52 \mathrm{~mm}$, (Table 1 ). 
Table 1. Means, standard deviations and confidence interval (in $\mathrm{mm}$ ) of tested analog and digitalized models

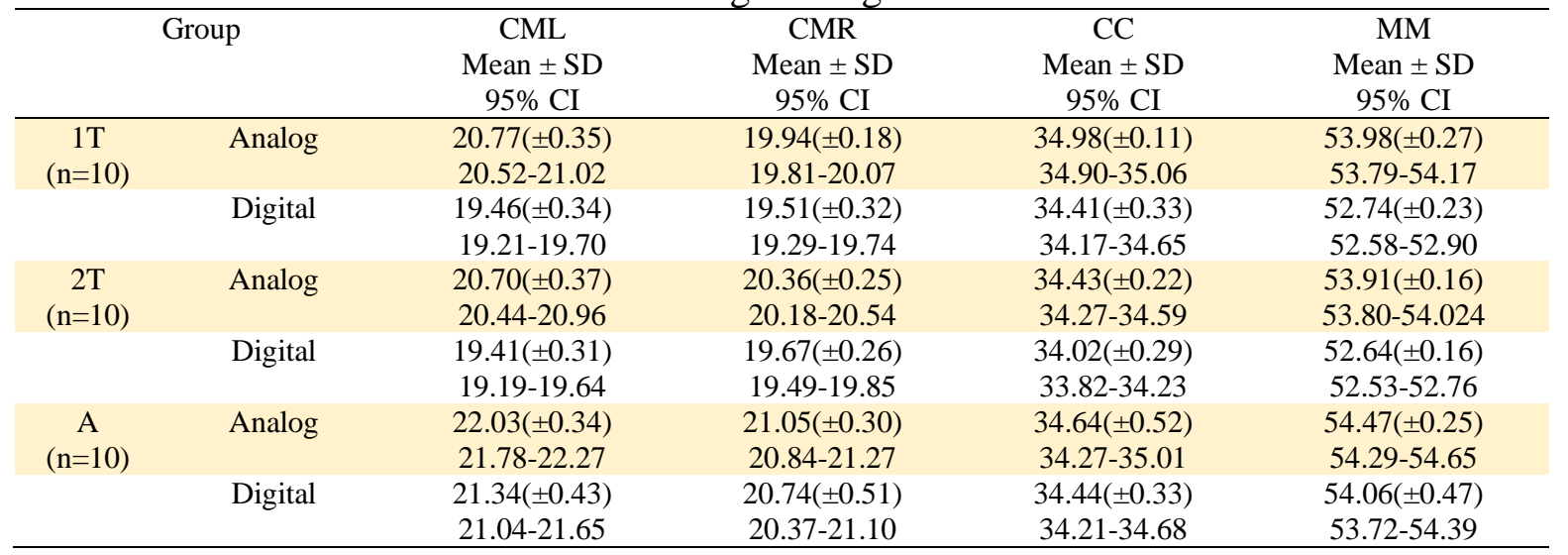

$1 \mathrm{~T}=$ models obtained from PDS impression in one-step technique, $2 \mathrm{~T}=$ models obtained from PDS impression in two-steps technique, $\mathrm{A}=$ models obtained from AAP impression, CMR- canine-molar right, CML- canine-molar left, CC- canine-canine, MM-molar-molar

Table 2 shows the differences between the means of three measurements for the master (reference) model and its digitalized version. As it could be observed, a high shrinkage of the scanned model, of more than $1 \mathrm{~mm}$ (1.96 $\mathrm{mm}$ for CMR), was noticed on antero-posterior and transversal posterior dimensions. For the transversal anterior measurement $(\mathrm{CC})$, a reduced extension $(-0.20 \mathrm{~mm})$ could be observed (Table 2). Due to these results, the digitalized version of the master model was not considered for further comparisons.

Table 2. Differences, in mm, between means for the master (reference) model and its digitalized version

\begin{tabular}{ccccc} 
Reference model & CML & CMR & CC & MM \\
& Mean & Mean & Mean & Mean \\
\hline Analog & 21.40 & 20.90 & 34.50 & 54.20 \\
Digital & 19.70 & 18.94 & 34.70 & 53.15 \\
Differences of means & 1.70 & 1.96 & -0.20 & 1.05 \\
\hline
\end{tabular}

CMR- canine-molar right, CML- canine-molar left, CC- canine-canine, MM-molar-molar

\subsection{Comparison between tested models and reference model}

The results of differences between mean values for analog and digital linear measurements and master model and their statistical significance are presented in Table 3.

Table 3. Difference between means and statistical significance of tested analog and digitalized models and reference model

\begin{tabular}{|c|c|c|c|c|c|}
\hline & \multirow[t]{2}{*}{ Group } & \multicolumn{4}{|c|}{$\begin{array}{l}\text { Differences, in } \mathrm{mm} \text {, between the means of tested and reference model in } \mathrm{mm} \\
\text { (statistical significance }-\mathrm{P} \text { values) }\end{array}$} \\
\hline & & CML & CMR & $\mathrm{CC}$ & MM \\
\hline \multirow[t]{2}{*}{$1 \mathrm{~T}$} & Analog & $-0.63(\mathbf{P} \leq \mathbf{0 . 0 0})$ & $-0.96(\mathbf{P} \leq \mathbf{0 . 0 0})$ & $\begin{array}{c}0.48 \\
(\mathbf{P} \leq \mathbf{0 . 0 0})\end{array}$ & $\begin{array}{l}-0.22 \\
(0.17)\end{array}$ \\
\hline & Digital & $-1.94(\mathbf{P} \leq \mathbf{0 . 0 0})$ & $-1.39(\mathbf{P} \leq \mathbf{0 . 0 0})$ & $\begin{array}{l}-0.09 \\
(0.43)\end{array}$ & $-1.46(\mathbf{P}<\mathbf{0 . 0 0})$ \\
\hline \multirow[t]{2}{*}{$2 \mathrm{~T}$} & Analog & $-0.70(\mathbf{P} \leq \mathbf{0 . 0 0})$ & $-0.54(\mathbf{P} \leq \mathbf{0 . 0 0})$ & $\begin{array}{l}-0.07 \\
(0.34)\end{array}$ & $-0.29(\mathbf{P} \leq \mathbf{0 . 0 0})$ \\
\hline & Digital & $-1.99(\mathbf{P} \leq \mathbf{0 . 0 0})$ & $\begin{array}{l}-1.23 \\
(\mathbf{P} \leq \mathbf{0 . 0 0})\end{array}$ & $-0.48(\mathbf{P} \leq \mathbf{0 . 0 0})$ & $-1.56(\mathbf{P} \leq \mathbf{0 . 0 0})$ \\
\hline \multirow[t]{2}{*}{ A } & Analog & $0.63(\mathbf{P} \leq \mathbf{0 . 0 0})$ & $0.15(\mathbf{0 . 0 1} *)$ & $0.14(0.42)$ & $0.27(\mathbf{0 . 0 4} *)$ \\
\hline & Digital & $-0.06(0.12)$ & $-0.16(0.11)$ & $0.06(0.91)$ & $-0.14(0.11)$ \\
\hline
\end{tabular}

$1 \mathrm{~T}=$ models obtained from PDS impression in one-step technique, $2 \mathrm{~T}=$ models obtained from PDS impression in two-steps technique, A=AAP, CMR- canine-molar right, CML- canine-molar left, CC- canine-canine, MM-molar-molar; Mann-Whitney test was applied: * Statistical significance: $\mathrm{P}<0.05$ 
The results showed for analog measurements that models registered a general shrinkage, except for the A group. The highest difference (shrinkage) noticed was $-0.96 \mathrm{~mm}(-960 \mu \mathrm{m})$ on the right caninemolar measure in one step PDS technique gypsum models (Table 3).

The digital measurements results indicated a general downsizing of the digital models, with statistically significant lack of trueness comparing to the reference model, except for the digitalized A group. The greatest lack of trueness (expansion) of $1.99 \mathrm{~mm}$ was measured at the canine-molar on the right side, at the two steps impression technique group of digitalized models (Table 3).

For trueness assessment, Mann-Whitney test was applied to find out if there was a statistically significant difference between the tested models and the reference model. As it could be observed in Table 3, the tested models obtained from PDS impressions, in one or two steps technique were proved to be statistically significant different from the reference model. The difference was also observed after digitalization.

Although the gypsum models obtained from AAP impression were statistically significant different at CML, CMR and MM linear measurements, their digitalized format registered no statistically significand differences as compared to the master (reference) model (Table 3).

\subsection{Difference between analog and corresponding digitalized models}

To assess the accuracy of the digitalized models comparing to the gypsum corresponding models, the differences between the means for each group of reference landmarks was calculated and the results are shown in Table 4. A transversally and sagittal shrinkage of the virtual models from their corresponding analogues gypsum models could be noticed (Table 4).

Table 4. Differences between the means and statistical significance of gypsum models and their corresponding digitalized models

\begin{tabular}{ccccc}
\hline \multirow{2}{*}{ Group } & \multicolumn{4}{c}{ Differences, in mm, between the means of analog and corresponding digitalized models } \\
& CML & CMR & CC & MM \\
\cline { 2 - 5 } & $1.31(\mathbf{P} \leq \mathbf{0 . 0 0})$ & $0.43(\mathbf{P} \leq \mathbf{0 . 0 0})$ & $0.57(\mathbf{0 . 0 1} *)$ & $1.24(\mathbf{P} \leq \mathbf{0 . 0 0})$ \\
1T & $1.29(\mathbf{P} \leq \mathbf{0 . 0 0})$ & $0.69(\mathbf{P} \leq \mathbf{0 . 0 0})$ & $0.40(\mathbf{0 . 0 1} *)$ & $1.27(\mathbf{P} \leq \mathbf{0 . 0 0})$ \\
A & $0.69(\mathbf{P} \leq \mathbf{0 . 0 0})$ & $0.31(\mathbf{0 . 0 4})$ & $0.20(0.18)$ & $0.41(\mathbf{0 . 0 3})$ \\
\hline
\end{tabular}

$1 \mathrm{~T}=$ models obtained from PDS impression in one-step technique, 2T= models obtained from PDS impression in two-steps technique, A=AAP, CMR- canine-molar right, CML- canine-molar left, CC- canine-canine, MM-molar-molar; Mann-Whitney test was applied, * Statistical significance: $\mathrm{P}<0.05$

\subsection{Comparison between the three types of models obtained from different impression techniques and materials}

Statistical significant differences were found between all analog and digitalized models, at all measured parameter, except for the analog models at CMR and MM between 1T and 2T, and at CC between A-1T and A2T; and for the digitalized models at CML, CMR and MM between 1T and 2T, and between $1 \mathrm{~T}$ and $\mathrm{A}$ at $\mathrm{CC}$ level (Table 5).

Table 5. Statistical significance between the three groups of analog and digital models

\begin{tabular}{|c|c|c|c|c|c|c|c|c|c|c|c|c|c|}
\hline \multirow{3}{*}{\multicolumn{2}{|c|}{ Groups }} & \multirow{2}{*}{\multicolumn{3}{|c|}{$\mathrm{CM}^{-}$}} & \multirow{2}{*}{\multicolumn{3}{|c|}{$\mathrm{CMR}$}} & \multirow{2}{*}{\multicolumn{3}{|c|}{$\mathrm{CC}$}} & \multirow{2}{*}{\multicolumn{3}{|c|}{$\mathrm{MM}$}} \\
\hline & & & & & & & & & & & & & \\
\hline & & $1 \mathrm{~T}$ & $2 \mathrm{~T}$ & $\mathrm{~A}$ & $1 \mathrm{~T}$ & $2 \mathrm{~T}$ & $\mathrm{~A}$ & $1 \mathrm{~T}$ & $2 \mathrm{~T}$ & A & $1 \mathrm{~T}$ & $2 \mathrm{~T}$ & $\mathrm{~A}$ \\
\hline \multirow{3}{*}{ Analog } & $1 \mathrm{~T}$ & & 0 & $\bar{X}$ & & $\mathbf{X}$ & $\mathbf{X}$ & & $\mathbf{X}$ & 0 & & 0 & $\mathrm{X}$ \\
\hline & $2 \mathrm{~T}$ & 0 & & $\mathbf{x}$ & $\mathbf{x}$ & & $\mathbf{x}$ & $\mathbf{x}$ & & 0 & 0 & & $\mathrm{X}$ \\
\hline & $\mathrm{A}$ & $\bar{x}$ & $\mathrm{x}$ & & $\mathbf{x}^{-}$ & $\mathbf{x}$ & & 0 & 0 & & $\mathbf{x}$ & $\mathbf{x}$ & \\
\hline \multirow{3}{*}{ Digital } & $1 \mathrm{~T}$ & & 0 & $\mathrm{X}$ & & 0 & $\mathbf{X}$ & & $\mathbf{X}$ & 0 & & 0 & $\mathrm{X}$ \\
\hline & $2 \mathrm{~T}$ & 0 & & $\mathrm{X}$ & 0 & & $\mathrm{X}$ & $\mathrm{X}$ & & $\mathrm{X}$ & 0 & & $\mathrm{X}$ \\
\hline & $\mathrm{A}$ & $\mathrm{X}$ & $\mathrm{X}$ & & $\mathrm{X}^{-}$ & $\mathrm{X}$ & & 0 & $\mathrm{X}$ & & $\mathrm{X}$ & $\mathrm{X}$ & \\
\hline
\end{tabular}

Statistical significance between test groups assessed according to one-way Anova with post-hoc Tukey's test applied for pairwise analysis. Levene's test was used to assess homogenity of variance: $0=$ no statistical difference, $X=$ statistical difference at $\mathrm{P}<0.05$. 1T = models obtained from PDS impression in one-step technique, $2 \mathrm{~T}=$ models obtained from $\mathrm{PDS}$ impression in two-steps technique, A=AAP, CMR- canine-molar right, CML- canine-molar left, CC- canine-canine, MM-molar-molar 


\subsection{Discussions}

For the polymeric materials used in dentistry, the performance requirements are tailored for their specific applications, but the fundamental principle of biomaterials is consistent: appropriate biomechanical properties, reduced volumetric changes, coupled with excellent biocompatibility and biological safety, the chemical structure of the polymer determining its properties, and the properties being closely related to their clinical applications [37-41].

Two type of impression materials widely used in daily practice were evaluated in the present study. PDS materials are recommended by the clinicians for fixed dental restorations, being more prone to longterm volumetric stability. On the other hand, irreversible hydrocolloids such as AAPs, recommended mostly in removable prosthodontics and orthodontics, despite of their low cost, ese of use and the ability to obtain relative precise impression, had a major drawback related to the ability to shrink or expand depending on the water content, making them long term unstable [42].

For the condensation-cured PDS, composed from a base paste, containing polymethyl siloxane fluid with a filler, and an activator paste of tetra-ethyl silicate (the cross-linking agent), the amount of activator paste used is extremely important for achieving accurate impressions; insufficient tetra-ethyl silicate lead to an incomplete cure, leaving a material with poor mechanical characteristics, and an excess of tetraethyl silicate also gives an incomplete cure, leaving many unreacted ethyl end-groups. Moreover, the release of volatile by-products, originating from the polymerization process (such as $\mathrm{R}-\mathrm{OH}$ ), will lead to a certain degree of contraction. Despite of the fact that the poly(dimethyl siloxane) impression materials condensation-cured used in the present study was described as a material of the last generation, with included pre-condensed dimension controller, which guarantees a greater flexibility, elastic recovery and dimensional stability for many days [1], a statistical significant shrinkage (contraction) of the full arch models was noticed, with both techniques used (Table 3 ).

The good results obtained with the AAP in the present study, could be explained by strictly following the producer's recommendations, therefore, the AAP conventional and digital models registered the better trueness comparing to silicon models. For PDS, the volumetric changes in the model were probably due also to difficulties in impression removal, linked to higher rigidity and hardness of elastomeric materials [43].

The digital models of the dentition can be obtained by either direct 3D scanning of the oral cavity, using intraoral scanners, or by indirect 3D scanning of cast models made from conventional impressions, using desktop (laboratory) scanners [44], or cone-beam computed tomography (CBCT) machines [45]. Despite of the advantages of the intraoral (direct) scanners over conventional impression methods, in terms of increased procedure comfort, and improved communication between patient, clinician, and dental laboratory, several clinical and economic factors limited their use. For indirect digitalization of casts or impressions, the extraoral laboratory (desktop) scanners are either tactile or optical. With a greater precision and significantly shorter scanning time [34], optical scanners uses electromagnetic wave, typically light, to capture the information of the models. The dental 3D scanner used in the present study is a Structured light scanner, considered, among other laboratory scanners using this technology, the best scanners because they can gather much more information per scan than can other types of non-contact scanners such as Laser light scanners or Confocal microscopy and confocal holography scanners [46,47]. The wide-field, high-resolution images obtained with the Structured light scanner, similar to the other non-contact scanners, are affected by the surface characteristics. For example, translucent surfaces return light to the scanner not only by reflection but also by refraction, which can alter the measurement [44]. This mechanism explained the great inaccuracy of the digitalized version of the reference model (Table 2). The reflective material of the typodont KaVo reference model did not allowed a precise scanning, therefore, the digitalized version of the model was not considered as digital reference in the present study.

Due to the extensive requirements of digitalization of conventional models, in partially digital workflows, a great number of studies were performed recently on the accuracy of full arch digital models [20,22,25,45,48,49], assessing different type of scanners used to digitalize the gypsum models [45], different scanning techniques [25], comparing different type of impression materials to digital 
impressions [20,22], but the evaluation of the factors involved in indirect digitalization such as the influence of the impression materials or techniques on the accuracy final digital model is limited.' The present study aimed to assess the accuracy of full arch models, obtained by pouring impressions from two different materials and two techniques frequently used for arch registration for implant planning, orthodontic treatment or prosthetic rehabilitation, before and after indirect digitalization.

In general, two modes can be used to analyse the accuracy of different conventional and digital techniques [50,51]: the first one consists of the comparison of the models (linear or volumetric) [52,53], and the second consists of the comparison of the marginal and internal fit of the final dental restorations.

Regarding the second evaluation mode, several in vitro studies reported results showing clinically acceptable fit of prosthetic rehabilitations obtained from a digital impression technique compared to conventional impressions [13,54-59], but it should be noted that these conclusions were based on the entire production process of the restoration evaluation.

In the present study models were compared using linear measurements to assess the antero-posterior and transversal shrinkage/expansion and to establish if these linear changes will be compensated after digitalization, using a desktop scanner. The volumetric three-dimensional superimpositions is recommended by some authors to analyse dimensional changes of impressions and models $[52,60,61]$. However, three-dimensional investigation procedures use a best-fit alignment which could mask distortions by moving the distorted models in the most optimal position to match the reference model. On the other hand, linear distance measurements provide information about the absolute deviation and was preferred in our in vitro investigation, in accordance to Kuhr's recommendations who stated that linear distance measurements are suitable for measuring trueness of full arch impressions for both conventional and digital impressions [61].

Another concern for accurate measurements is the landmark locations. Rossini et al. reported that the greatest proportion of errors in linear measurements occurred during the landmark-locating step, due to the lack of physical marks. For reliable comparative measurements, hemispherical landmarks (1.4-mm diameter) were grinded on the cusp tip of the right and left canines and on the mesio-vestibular cusps tips of the left and right first molar. The diameter of the grinded landmarks could not be reduced without affecting their reproducibility in the impressions, gypsum and virtual models. Many other studies reported the use of physical landmarks, usually balls, with diameters between $1.4 \mathrm{~mm}$ [62] and $5 \mathrm{~mm}$ [63], but Keul and Guth proposed a straight metal bar connecting the second molars of the left and right maxillary hemi-arch. However, for the retention of the landmarks, luting cement is needed an could lead to further inaccuracy.

Kim et al. uses the measurement of surface reference points with high trueness coordinate measurement machines (CMMs) [25], but with some shortcomings such as lack in scan speed and less accurately in measuring freeform surfaces because of the geometric size and shape of the tip (probe) [52]. However, in our study the analog measurements of the typodont model was considered as references, therefore a digital caliper was used for measuring all analog models and the digital models were measured in Exocad software, with the dedicated measurement tool. According to previous reports, the differences between the golden standard caliper linear measurements on gypsum models and those from digital models were considered clinically insignificant $[13,64,65]$.

Precision was evaluated taking into consideration the reproducibility of the analog and digital models of each impression type group. The highest reliability, evidenced by lowest standard deviation, was observed in 1T and 2T gypsum models, at the transversal anterior region (CC) from 1T technique $( \pm 0.11$ $\mathrm{mm})$ and at the transversal posterior region $(\mathrm{MM})$ for $2 \mathrm{~T}$ technique $( \pm 0.16 \mathrm{~mm})$, respectively. The lowest reproducibility was $\pm 0.52 \mathrm{~mm}$ (for transversal CC measurements), registered for the gypsum models poured from AAP impressions. For the digitalized models, standard deviations were between $\pm 0.16 \mathrm{~mm}$ (MM 2T PDS group and CMR A group) and $\pm 0.51 \mathrm{~mm}$ (MM A group) (Table 1). However, in all analysed data, the maximum standard deviation was $\pm 0.52 \mathrm{~mm}$, considered in the limit of clinical acceptability $[13,64,65]$. 
Trueness was evaluated by comparing each different group to the master (reference) model. All test measurements were different from the master, with a general shrinkage on the gypsum models, except for the anterior region (transversal CC) for 1T silicon and for all A group, were a slight extension was noticed (Table 3). These results are partially in consensus with Vitti's study [66], where all distances measured showed altered dimensions with significantly negative linear changes (shrinkage). The most important difference was $0.96 \mathrm{~mm}(960 \mu \mathrm{m})$ on the right canine-molar sagittal measurement in 1T PDS technique. This value was higher comparing to other studies [10] reporting differences up to $50 \mu \mathrm{m}$ in the posterior region.

Related to the impression technique, models poured from PDS impression presented differences from the reference model in sagittal dimension, with higher values for one step technique. The models poured from AAP impression showed the smallest discrepancies related to the master model. The lower trueness of condensation PDSs impression materials could be explained by evaporation effect of volatile components such as ethanol, that could lead to dimensional stability and accuracy alteration [67]. This result are different from Vitti and co-workers findings [66] who reported no differences among the impression techniques.

After digitalization, the downsizing of the virtual files was even more observable (Table 3), and the dimensions reduction is not symmetrical. The asymmetrical differences were also observed by Ender and co-workers who reported digital models with highest posterior deviations located only at one side of the models [10].

Sagittal errors in virtual models was identified in other studies, as well [68,69], digital impression technique accuracy depending on the length of the scanning area [69]. The different results of the virtual models' measurements resulted from the digital impression in a laboratory scanner could be explained by the different distance and area exposure of the model in the scanning process. Other studies also reported asymmetrical errors of digital models in the distal molar area, more predominant in one side [10,22].

All models, analog and digitalized, were statistically significant different from the reference model (Table 3) except for the digitalized A group of models. The best compensation of shrinkage/expansions after digitalization was observed for the models poured from AAP.

The extent of compensation was assessed by comparing digitalized to corresponding analog models (Table 4). A difference between $0.20 \mathrm{~mm}$ and $1.31 \mathrm{~mm}$ was observed between the means of analog and corresponding digitalized models, a longitudinally and sagittal shrinkage of the virtual models being evidenced. This shrinkage is statistically significant for all digitalized models, Table 4.

When the three group of models were compared, statistically significant differences were observed between all analog and digitalized models, at all measured parameter (Table 5) for the digitalized models. The main differences between the three types of models, registered at CMR measurement in our research could be related to the impression removal technique.

With few exceptions, there were statistically significant differences between most of the models and the reference model, in the present study, with regard to the measured parameters. Therefore, the null hypothesis had to be rejected.

A general "shrinkage" of the digitalized models was observed after scanning comparing to the reference model (Table 1 and Table 2). This fact was also reported in previous studies [25,70,71] and researchers suggested that this tendency of "downsizing" of the digital models might be due to the algorithms used in the conversion software [71,72]. Digital models with statistically significant smaller measurements than the true measurements were also obtained by Kim et al. who used for digitalization of plaster models intraoral scanners, desktop scanners and CBCT scan [25], downsized virtual models being obtained with all digitalization techniques. However, it should be note that, in the present study, when AAP was used as impression material, the errors were "compensated" and the obtained digital model was not statistically significant different to the reference model, in all measured parameters (Table 3).

However, we must consider that in our study the virtual models were obtained by indirect digitalization of the analog models. Errors within the maximum allowable tolerance for dimension 
changes were obtained with AAP by direct scanning the impression by Kim et al., therefore, they proposed the possibility of digitization of AAP impressions in the future with good economic impact [42]. The conventional models obtained from PDS impression, using both techniques (1T and 2T) registered a general "shrinkage" also reported by other researchers [42], and the dimensional changes were amplified by digitalizing the models, leading to virtual model with less trueness. No statistically significant influences regarding accuracy were observed when different impression techniques were used (1T versus 2T).

Digitalization of the gypsum models is still required in the CAD/CAM workflow in a large number of dental fields, and for increasing trueness, the use of an impression material with less "shrinkage" or slight "expansion", such as AAP in the present study, that will compensate the digital cast volumetric changes, could be an option for increasing accuracy of the final digital file.

Study limitations: two-dimensional measurements have been used to determine the geometrical changes. Because the measurements were taken at a limited number of sites the object is only partly analysed for geometrical changes. Moreover, only two impression materials were analysed and three impression techniques. These materials were preferred due to the fact that most preliminary impressions for dental implants planning and insertion, orthodontic analysis and treatment planning and also prosthetic reconstruction planning are performed with these impression materials and techniques. Further studies involving other impression materials and their influence on the digital model need to be done.

\section{Conclusions}

In the limit of our study, the following conclusions were drawn: a statistically significant difference was found between most of the models and the master model. However, through digitalization, some of the errors were compensated. The models obtained from digitalization of the models poured from AAP (Alginic Acid Polymer) impression registered the highest accuracy compared with the ones poured from condensation-cured PDS (Poly-dimethyl siloxane), with no statistically significant difference from the reference model.

\section{References}

1. DE CESERO, L., NOGARETT, L.M., MOTA, E.G., FRACASSO, L.M., DE ARAUJO, C.D.R.P., Polimeros, 23(4), 2013, 473-476.

2. XU, X., HE, L., ZHU, B., LI, J., LI, J., Advances in polymeric materials for dental applications. Polym. Chem. 8, 2017, 807-823.

3. SAKAGUCHI, R.L., POWERS, J.M., Craig's restorative dental materials; Elsevier Health Sciences, 2012; ISBN 0323082513.

4.PIWOWARCZYK, A., OTTL, P., BUCHLER, A., LAUER, H.C., HOFFMANN, A., Int. J. Prosthodont. 15(2), 2002, 168-174.

5.CHANDRAN, D.T., JAGGER, D.C., JAGGER, R.G., BARBOUR, M.E., Proceedings of the BioMedical Materials and Engineering; 20(5), 2010, 243-249.

6.THONGTHAMMACHAT, S., MOORE, B.K., BARCO, M.T., HOVIJITRA, S., BROWN, D.T., ANDRES, C.J., J. Prosthodont.; 11(2), 2002, 98-108.

7.VAN NOORT, R., BARBOUR, M.E., Introduction to Dental Materials, $4^{\text {th }}$ edition, Elsevier Health Sciences, 2013; ISBN 0723436592.

8. SAMET, N., SHOHAT, M., LIVNY, A., WEISS, E.I., J. Prosthet. Dent., 94(2), 2005, 112-117.

9. CRISTACHE, C.M., GURBANESCU, S., Int. J. Dent. 2017, doi:10.1155/2017/4292081.

10. ENDER, A., MEHL, A., Quintessence Int. (Berl), 46(1), 2015, 9-17.

11. ***ISO standard 5725-2:2019 Available online: https://www.iso.org/obp/ui/\#iso:std:iso:5725:-2:ed2:v1:en (accessed on 15.06.2020).

12. ENDER, A., MEHL, A., Prosthet. Dent, 109(2), 2013, 121-128.

13. BOOTVONG, K., LIU, Z., MCGRATH, C., HAGG, U., WONG, R.W.K., BENDEUS, M., YEUNG, S., Eur. J. Orthod., 32(5), 2010, 589-595. 
14. BENIC, G.I., MUHLEMANN, S., FEHMER, V., HAMMERLE, C.H.F., SAILER, I., J. Prosthet. Dent. 116(5), 2016, 777-782.

15. CICCIU, M., FIORILLO, L., D’AMICO, C., GAMBINO, D., AMANTIA, E.M., LAINO, L., CRIMI, S., CAMPAGNA, P., BIANCHI, A., HERFORD, A.S., CERVINO, G., Materials (Basel), 13(8),2020, 1982.

16. VECSEI, B., JOOS-KOVACS, G., BORBELY, J., HERMANN, P., J. Prosthodont. Res., 61(2), 2017, 177-184.

17. SU, T.S., SUN, J., J. Prosthodont. Res. 59(4), 2015, 236-242.

18. RUNKEL, C., GUTH, J.F., ERDELT, K., KEUL, C. Clin. Oral Investig. 24(3), 2020, 1249-1257.

19. KEUL, C., GUTH, J.F., Clin. Oral Investig. 24(2), 2020, 735-745.

20. MALIK, J., RODRIGUEZ, J., WEISBLOOM, M., PETRIDIS, H., Int. J. Prosthodont. 31(2), 2018, 107-113.

21. VANDEWEGHE, S., VERVACK, V., VANHOVE, C., DIERENS, M., JIMBO, R., DE BRUYN, H., Int. J. Periodontics Restor. Dent. 35(1), 2015, 115-121.

22.ENDER, A., ATTIN, T., MEHL, A., J. Prosthet. Dent. 115(3), 2016, 313-320.

23. JOOS-KOVACS, G., VECSEI, B., KORMENDI, S., GYARMATHY, V.A., BORBELY, J., HERMANN, P., BMC Oral Health 280, 2019.

24. ROSSINI, G., PARRINI, S., CASTROFlORIO, T., DEREGIBUS, A., DEBERNARDI, C.L., Am. J. Orthod. Dentofac. Orthop., 149(2),2016, 161-170.

25. KIM, Y.H., HAN, S.S., CHOI, Y.J., WOO, C.W., Appl. Sci. 10(8), 2020, 2741.

26. KIHARA, H., HATAKEYAMA, W., KOMINE, F., TAKAFUJI, K., TAKAHASHI, T., YOKOTA, J., ORISO, K., KONDO, H., J. Prosthodont. Res. 64(2), 2020, 109-113.

27.CRISTACHE, C., M., IONESCU, C., BURliBASA, M., CRISTACHE, G., ILIESCU, A. A., DUMITRIU, H., T., Metal. Int. 14, (SPEC. ISS.16), 2009, p.59.

28. CRISTACHE, C., M., IONESCU, C., CRISTACHE, G., IONESCU, I., ILIESCU, A., A., BURLIBASA, M., Metal. Int. 14, (SPEC. ISS.16), 2009, p. 27.

29. COOK, W., J. Biomed. Mater. Res. 20(1), 1986, 1-24.

30. CHO, S.H.; SCHAEFER, O.; THOMPSON, G.A.; GUENTSCH, A., J. Prosthet. Dent. 113(4), 2015, 310-315.

31. MANDIKOS, M.N., Aust. Dent. J. 43(6), 1998, 428-434.

32. AL-ZAREA, B.K., SUGHAIREEN, M.G., J. Contemp. Dent. Pract. 12(3), 2011, 208-215.

33. MARKOVIC, D., PUSKAR, T., HADZISTEVIC, M., POTRAN, M., BLAZIC, L., HODOLIC, J., Contemp. Mater., 1(3), 2012, 105-110.

34. OKAWA, T., ABE, S., NAKANO, M., OKA, K., HORIKAWA, E., MATSUKA, Y., KAWANO, F., Dent. Mater. J. 12, 2020, 2019-2157.

35. LAVORGNA, L., CERVINO, G., FIORILlO, L., DI LEO, G., TROIANO, G., ORTENSI, M., GALANTUCCI, L., CICCIU, M., Int. J. Environ. Res. Public Health 16(24),2019, 5139.

36. KAIHARA, Y., KATAYAMA, A., ONO, K., KUROSE, M., TOMA, K., AMANO, H., NIKAWA, H., KOZAI, K., Eur. J. Paediatr. Dent. 15(2), 2014, 137-142.

37.TOTU, E. E., CRISTACHE, C. M., ISILDAK, S., TAVUKCUOGLU, O., PANTAZI, A., ENACHESCU, M., BUGA, R., BURLIBASA, M., TOTU, T., Mater. Plast., 55(4), 2018, 616.

38. PANTAZI, A., TOTU, E. E., DOROBANTU, D., CRISTACHE, C. M., ENACHESCU, M., Mater. Plast., 55(4), 2018, 634.

39.CRISTACHE, C. M., GROSU, A. R., CRISTACHE, G., DIDILESCU, A. C., TOTU, E. E., Mater. Plast., 55(4), 2018, 555-562.

40. TOTU, E. E., CRISTACHE, C. M., VOICILA, E., OPREA, O., AGIR, I., TAVUKCUOGLU, O., DIDILESCU, A. C., Mater. Plast., 54(4), 2017, 666.

41. TOTU, E. E., CRISTACHE, C. M., VlasceANU G., JOSCEANU, A. M., NECHIFOR, A. C., Mater. Plast., 56(1), 2019, 252-255.

42. KIM, S.R., LEE, W.S., KIM, W.C., KIM, H.Y., KIM, J.H., Dent. Mater. J. 34(6), 2015, 835-840. 
43. WALKER, M.P., ALDERMAN, N., PETRIE, C.S., MELANDER, J., MCGUIRE, J., J. Prosthodont. 22(5), 2013, 362-366.

44. RAMIRO, G.P., HASSAN, B., NAVARRO, A.F., CORONEL, C.A., CORTES, A.R.G., BAPTISTA, O.H.P., ZAMBRANA, N.R.M., Digitalization in Restorative Dentistry. In Digital Restorative Dentistry, Springer 2019, 7-39.

45.NOWAK, R., WESEMANN, C., ROBBEN, J., MUALLAH, J., BUMANN, A., Quintessence Int. (Berl).,20, 2017, 667-676.

46. DE VILlAUMBROSIA, P.G., MARTINEZ-RUS, F., GARCIA-OREJAS, A., SALIDO, M.P., PRADIES, G., J. Prosthet. Dent., 116(4), 2016, 543-550.e1.

47. AHN, J.S., PARK, A., KIM, J.W., LEE, B.H., EOM, J.B., Sensors (Switzerland) 17(7), 2017, 1634. 48. TANCU, A.M.C., PANTEA, M., TOTAN, A., TANASE, M., IMRE, M., Mater. Plast. 56(1), 2019, 51-54.

49. ROMANEC, C., ROSU, S., MACOVEI, G., SCUTARIU, M.M., DRAGOMIR, B., OLTEANU, N.D., Mater. Plast., 55(4), 2018, 668-690.

50. PATZELT, S.B.M., EMMANOUILIDI, A., STAMPF, S., STRUB, J.R., ATT, W., Clin. Oral Investig. 18(6), 2014, 1687-1694.

51. VAN DER MEER, W.J., ANDRIESSEN, F.S., WISMEIJER, D., REN, Y., PLoS One, 7(8), 2012, e43312.

52. PAGANO, S., MORETTI, M., MARSILI, R., RICCI, A., BARRACO, G., CIANETTI, S., Materials (Basel). 12(12), 2019, 1958.

53. CRISTACHE, C.M., TOTU, E.E., BEURAN, I.A., CARAUSU, E.M., TOTU, T., BURLIBASA, L., Rev. Chim., 70(10), 2019, 3753-3758.

54. SEELBACH, P., BRUECKEL, C., WOSTMANN, B., Clin. Oral Investig. 17, 2013, 1759-1764.

55. SU, T.S., SUN, J., J. Prosthet. Dent. 116(3), 2016, 362-367.

56. KOLLMUSS, M., KIST, S., GOEKE, J.E., HICKEL, R., HUTH, K.C., Clin. Oral Investig. 20(4), 2016, 791-797.

57. ANADIOTI, E., AQUILINO, S.A., GRATTON, D.G., HOLlOWAY, J.A., DENRY, I.L., THOMAS, G.W., QIAN, F., J. Prosthet. Dent. 113(4), 2015, 304-309.

58. ALMEIDA E SILVA, J.S., ERDELT, K., EDELHOFF, D., ARAUJO, E., STIMMELMAYR, M., VIEIRA, L.C.C., GUTH, J.F., Clin. Oral Investig. 18(2), 2014, 515-523.

59. CAPUTI, S., VARVARA, G., J. Prosthet. Dent. 99(4), 2008, 274-281.

60. LUTHARDT, R.G., KUHMSTEDT, P., WALTER, M.H., Dent. Mater. 19(1), 2003, 19-24.

61. KUHR, F., SCHMIDT, A., REHMANN, P., WOSTMANN, B., J. Dent. 55, 2016, 68-74.

62. EMIR, F., PISKIN, B., SIPAHI, C., J. Prosthet. Dent. 117(3), 2017, 410-418.

63. VOGEL, A.B., KILIC, F., SCHMIDT, F., RUBEL, S., LAPATKI, B.G., J. Orofac. Orthop. 76(4), 2015, 351-365.

64. BELL, A., AYOUB, A.F., SIEBERT, P., J. Orthod. 30(3), 2003, 219-223.

65. DALSTRA, M., MEISEN, B., J. Orthod. 36(1), 2009, 36-41.

66. VITTI, R.P., DA SILVA, M.A.B., CONSANI, R.L.X., SINHORETI, M.A.C., Braz. Dent. J. 24(5), 2013, 498-502.

67. CHRISTENSEN, G.J., J. Am. Dent. Assoc. 128(7), 1997, 1026-1081.

68. MEHL, A., ENDER, A., MORMANN, W., ATTIN, T., Int. J. Comput. Dent., 12, 2009, 11-28.

69. LUTHARDT, R.G., LOOS, R., QUAAS, S., Int. J. Comput. Dent. 8(4), 2005, 283-294.

70. JIANG, T., LEE, S.M., HOU, Y., CHANG, X., HWANG, H.S., Korean J. Orthod. 46(3), 2016, 129136.

71. ABIZADEH, N., MOLES, D.R., O’NEILL, J., NOAR, J.H., J. Orthod. 39(3), 2012, 151-159.

72. MAROUA, A.L., AJAJ, M., HAJEER, M.Y., J. Contemp. Dent. Pract. 17(4), 2016, 294-299.

$\overline{\text { Manuscript received: 06.08.2020 }}$ 